\title{
中国高考与德国 Abitur 之比较
}

\section{Comparison of Chinese College Entrance Examination and German Abitur}

\author{
张庭维 陈嘉楠 赵怡楠 周智利 \\ Tingwei Zhang Jianan Chen Yinan Zhao Zhili Zhou \\ 宁波大学 中国·浙江 宁波 315000 \\ Ningbo University, Ningbo, Zhejiang, 315000, China
}

\begin{abstract}
摘 要: 由于德国教育理念和Abitur 制度的特殊性, 社会上一直存在着德国不需要高考的误解。论文通过查阅大量文献, 深入了解德国高校人才选拔的制度体系，一方面对比两个国家高考体制的利弊，立足中国实际吸取德国多方位培养创新型 人才的经验; 另一方面，通过对德国 Abitur 的深入研究，消除“德国不需要高考” 的误解。

Abstract: Due to the particularity of the German educational philosophy and the Abitur system, there has always been a misunderstanding that Germany does not require college entrance examinations. Through consulting a large number of literatures, this paper has an in-depth understanding of the talent selection system in German universities. On the one hand, it compares the advantages and disadvantages of the college entrance examination system in two countries, and based on the actual situation in China, it draws on Germany' s experience in cultivating innovative talents in various aspects. On the other hand, through the in-depth study of German Abitur, the misunderstanding that "Germany does not need the college entrance examination" is eliminated.
\end{abstract}

关键词: 高考; 德国; Abitur

Keywords: college entrance examination; Germany; Abitur

DOI : $10.36012 /$ sde.v2i12.2586

\section{1 引言}

教育, 是一个国家的立国之本，也是一个民族振兴、社 会进步的基石。德国二战后的迅速崛起到如今作为工业强国 依然在世界舞台上屹立不倒的重要影响因素之一即为教育。 由于德国教育体制和教育理念的特殊性, 社会上一直存在着 德国不用高考的误解与偏见。通过将德国 Abitur 和中国高 考进行比较研究, 有助于消除这一误解。近年来, 中国一直 在推进高考体制改革。教育现代化、教育国际化，是中国教 育发展趋势, 高考制度也要与时俱进, 吸取各国先进教育理 念精髓, 以进一步改进。因此了解德国高校选拔人才的制度 体系，对中国不断完善高考制度有重大借鉴意义。

\section{2 德国 Abitur 和中国高考的概念比较}

\section{1 定义比较}

德国高校招生考试通常被称为 “Abitur” 或 “Abiturzeugnis”, 是德国或国外公认的德国学校的离校生通 过连续 12 至 13 年的学习时间, 成功通过了最终毕业考试 “Abiturprüfung” 的一份教育证书。
中国普通高等学校招生全国统一考试, 简称高考, 是 中华人民共和国合格的高中毕业生或具有同等学力的考生 参加的选拔性考试。

\section{2 意识形态比较}

中国是人民民主专政国家，由中央统一管辖，各省市 在统一时间组织高考, 目前大部分省市高考使用全国卷，几 个省市自主命题。

德国是联邦制国家，各州在文化教育 (包括考试领域) 享有极大的自主权, 因此德国不实行全国统一的高考制度 ${ }^{[1]}$ 。 同时与欧美其他国家的精英教育不同,与中国的基础教育(可 看作是精英教育的全民化）也不同，德国教育更注重 “普适 化”。虽然德国也有 TU9 理工大学联盟、精英大学计划, 但 归根结底, 在德国人的心目中, 并不对大学有明确的三六九 等之分。Maxim Baer 曾经在《International Corporations as Actors in Global Governance》一书中对 92 位来自德国和法 国的高级管理者进行调研。在问到 “德国/法国是否是精 英化教育” 时， $73 \%$ 的人认为法国是精英化教育，而仅有 $11 \%$ 的人认为德国存在精英化教育的迹象。结果表明德国 
人认为 “水涨则船高”, 将底层建设好, 整体就会跟着提升。 对于企业和社会来讲, 培养较多数可用之才, 远远胜过于仅 仅培养极少数的拔尖者。

\section{3 德国 Abitur 和中国高考的形式比较 3.1 中国高考形式}

目前中国的高考政策可分为以下 4 类 :

(1)大部分省市区实行 “ $3+X$ ”高考模式。

“3”指 “语文、数学、外语”, “X”指由学生根据自己 的意愿, 自主从文科综合和理科综合 2 个综合科目中选择一 个作为考试科目。总分 750 分 (语文 150 分, 数学 150 分, 外语 150 分, 文科综合/理科综合 300 分)。

(2)江苏省（2008 年 - 2020 年) 实行 “3+学业水平测试 + 综合素质评价” 高考模式。

“3”指语文、数学、外语, 语文 160 分 (文科加考 40 分加试题)、数学 160 分 (理科加考 40 分加试题)、外语 120 分, 满分 480 分。

学业水平测试选修科目考试为物化生政史地 $6 门$ 门科目, 各科原始满分 120 分。文科考生必考历史, 理科考生必考物 理, 再从化学, 生物, 政治, 地理中任选一门, 学业水平测 试选修科目按原始得分排名实行等级计分。

学业水平测试必修科目考试: 考生需参加未选为学业水 平测试选修科目的 5 门必修科目, 另外信息技术只作为学业 水平测试必修科目, 学业水平测试必修科目按 60 分及以上 为合格, 其余为不合格作为评价。普通类考生学业水平测试 必修科目须全部达到 “合格”, 方可参加高考和选修科目测试。

3 、浙江省、上海市实行 “ $3+3$ ” 高考方案

上海市方案 :

必考科目: 语文/数学/外语每科 150 分, 其中英语一 年两考, 取最高分。选考科目: 物理, 化学, 生物, 政治, 历史, 地理选 $3 门$ 门, 每科 70 分, 按照 $\mathrm{A}+、 \mathrm{~A} \cdots \cdots \cdot$. 比例给分, 总分 660 分。

浙江省方案 :

必考科目: 语文/数学/外语每科 150 分。选考科目:政治、 历史、地理、物理、化学、生物、技术, 学生要选择 3 门作 为高考选考科目。

选考科目每年安排 2 次考试, 分别在 4 月和 10 月 (目 前已改革至 6 月和 1 月) 进行。每门总共安排 3 次统一考试, 考生可自行决定参加时间, 每门科目最多参加 2 次, 选考科
目成绩实行等级赋分, 如成绩在前 $1 \%$ 者赋分 100 分加入高 考总成绩。总分 750 分。

4、河北、辽宁、江苏、福建、湖北、湖南、广东、重 庆等 8 省市实行 “ $3+1+2$ ” 高考模式

从 2018 年秋季入学的高中一年级学生开始实施, 新高 考改革逐步全面展开。“3 $3+1+2$ ”模式指 : 语文、数学、外 语是 3 门必考科目, 物理、历史选择 1 科作为必考, 但两门 只能选择一门, 然后从政治、地理、生物、化学四门任意选 择 2 门来学习。

\section{2 德国 Abitur 形式}

德国高校在录取时采取综合评价体系，即会综合考量 学生的高中毕业会考成绩、学生从十二年级到十三年级 (相 当于我国高二、高三）的全部学科成绩及个人综合素质, 综 合素质包括如团队精神、社区服务经历、荣誉奖励等。

德国没有统一高考时间, 中学生只要完成 $\mathrm{Abi}$ 的考试 获得毕业证书就可以申请大学, 毕业证书上载明的成绩由两 个部分构成: 各州统一的毕业考试 (Abiturprüfung) 和平时 的学习成绩。两者经过不同权重的相加, 获得 1-4 分即可获 得毕业证书 (1.0 分为满分)。

学生高中两学年的全部学科成绩按照 $0-15$ 分的分数 计算, 通常由笔试和口试各占 $50 \%$ 构成。口试成绩分数由 两个方面评定 : 平时的小测验成绩和课堂表现，各占 $50 \%$ 。 课堂表现主要涉及学生上课是否积极发言、做笔记、准备专 题报告、进行课堂实验等 ${ }^{\left[{ }^{[}\right.}$。学生高中两学年的全部学科成 绩通过换算在高校录取总成绩中占比达到将近 $2 / 3$, 平时成 绩记录了学生高中阶段所有课程的学习状况, 学生申请大学 时能够较为全面地展现自身的综合实力、学科兴趣、个人特 质等, 而不是仅靠一次书面考试定 “终身”。

德国高中设置的课程分为语言艺术类、科学类、社会 科学类三大类, 德国 Abitur 考试科目就是在其中选择, 分 为主科和副科, 主科的分数权重较大。大部分联邦州的学生 选择 2 门主科 (一门外语、一门科学类), 少数联邦州 (如 Rheinland-Pfalz (莱茵兰 - 普法尔茨)) 的学生选择 3 门主科。 与中国以语数英为主，物化生政史地为辅的教育现状不同， 德国学生主科的选择性更大, 除了上述与中国相同的科目, 还有德语、第二外语、政治和经济、宗教/伦理 / 哲学、体育、 音乐 / 戏剧 / 美术等。

Abitur 要求每个学生必须参加 5 门学科的考试, 其中 3 
门笔试, 2 门口试, 且必须涵盖上述这三大类学科。两门主 科必须参加笔试。因此对剩下学科选择的要求为——德语和 数学为必考; 唯一笔试的副科不能与主科的两门是同一类的。

此外还有选修课的点数认定, 根据不同权重, 最终学 生获得以 900 分为满分的总成绩, 再

通过点数换算表, 将所得的点数 (Punkte) 转化成最终 的 Abitur 成绩（Note）。

德国 Abitur 政策中并没有为农村学生和少数民族学生 制订的特殊优惠政策。高校录取标准不涉及申请者的年龄、 民族、身体是否残疾和家庭经济状况如何等因素, 完全根据 招生专业制定的录取条件和学生成绩进行录取。另外, 德国 中小学也没有 “优秀学生干部” “三好学生” 和音体美考级, 因此没有特长生等录取加分做法。

\section{4 德国 Abitur 和中国高考的利弊比较}

德国的 Abitur 政策与其他欧美国家不甚相同，因此社 会上一直存在 “德国上大学不用选拔” 这样的偏见, 事实上 并非如此。Abitur 不仅仅是一次的考试, 更是对德国学生两 年的考验, 也是对学生综合素质的评判。德国这一体系更加 追求的是一贯的优秀, 而非 “临时抱佛脚”。尽管德国的大 学没有重点、非重点之分, 大学也没有统一的分数线, 但各 大学各专业对 Abitur 的分数要求都不一样。由于存在医科 等热门专业录取人数配额制度, 每年想要进入知名大学王牌 专业的学生们, 同样竞争得头破血流。不仅需要令人刮目相 看的中学毕业考试成绩单, 最好还能有足够优秀的海外交流 学习经验和出色的实习表现。 ${ }^{[6]}$

中国高校招生历经几次改革成效显著，在我国这样一 个幅员辽阔的国家无疑是一种最有效的量才、选才制度, 给 了偌大中国所有考生一个起码的 “公平”。近年来, “三位一 体” “自主招生” 等多样化高考录取形式的出现, 也给了中 国考生更多的选择和机会。但是不可否认的是, 最根本录取 的依据还是最终的高考成绩。中国传统的教育体系很明显地 将学生束缚在具有条框性质的课本之中, 从小学的义务教育 开始, 老师家长都以成绩论 “英雄”, 这也导致了大多数中 国学生缺乏创新精神，桎梏于应试教育刻板的牢笼。

因此我国需要改革的不仅仅是高考政策, 国家经济转 型也对我国的教育管理体制提出了新的要求, 更加强调创新 精神的突破和模式的多样。通过对西方中学及高校教育体系 无其是通过对德国教育的方式和结构的了解与分析，笔者认
为有以下可改进的方面 :

首先, 应当注重高校招生与教学的具体结合。德国高 校对于招生拥有较强的自主权, 可以在会考的基础上对学生 进行面试或提出相关录取条件。中国高校的招生通常由教育 部主持, 进行垂直管理, 依托于行政制度, 弱化了与高校教 育具体方向的结合。

其次, 中国高校体系较为单一, 绝大多数采取单一高 考分数进行录取。德国教育在毕业考试分数之外也同时兼顾 学生的具体素质, 平时成绩等。虽然以目前中国实际情况而 言, 存在量化困难等状况, 但这种知识、能力和素质并重的 全人格学力观仍不失为一种改革方向。

最后，中国近期的高等院校招生改革中，在科目设置上已 经趋向多元化，但仍应当继续注重考试科目的设置和考试范围 的扩大, 真正体现学生个性和能力。同时就目前而言, 中国高 校具体专业的考试科目设置相对固化，缺乏特色和层次，应当 鼓励高校在招生的科目设置上结合自身办学特色增强针对性。

\section{5 结论}

中国若效仿德国做到完全取消统一考试,新的 “高考不公” 的呼声可能将会产生。中国高考作为广大学子千军万马过的独 木桥，自然在国人心中有不轻的分量，而高考就是将注意力集 中在学习成绩上。德国作为西方代表性国家, 虽然不执著于学 习成绩, 但是事实上它提出了更高的要求 : 学生不仅要学习成 绩过得去, 还要在领导才能、外语水平、打工经验、社区服务 的经历、荣誉奖状有突出的才能。中国高考选拔的是成绩优异 的创新型人才, 而德国 Abitur 选择的是多方面突出的复合型人 才，两者虽然侧重点不同，但其目的确是大同小异。

\section{参考文献}

[1] 赵肖. 中美高考招生考试制度之比较研究 [J]. 科教导刊,2017 ( 23 ) :45.

[2] 牛学敏。德国高校招生管理体制及其对我国的借鉴 [J]. 中国考 试 (研究版),2007 (12):48-53.

[3] 修春民. 德国高校招生政策基本情况及发展趋势调研 [J]. 世界 教育信息, 2015 （4）:22-23

[4] 马晓倩. 他山之石: 国外 “高考” 长啥样 ?-- 德国 [J]. 青春期 健康 , 2015 (9) : 16-17.

[5] 修春民: 《德国高校招生政策基本情况及发展趋势调研》，《世 界教育信息》2015 年 04 期

[6] 马晓倩: 《他山之石: 国外 “高考” 长啥样 ?-- 德国》, 《青 春期健康》2015 年 9 期 